\title{
Measurement-based electrical parameters of power transformers for Frequency Response Analysis interpretation - Part II: Winding analysis
}

\author{
Dinh Anh Khoi Pham
}

\begin{abstract}
For a practical Frequency Response Analysis (FRA) interpretation applicable to power transformers, frequency dependent electrical parameters of the core and windings in broad frequency range should be identified through nondestructive measurements. Since the core parameters are determined in Part $I$, electrical parameters of windings (resistances, capacitances) and leakage paths surrounding windings (leakage/zero-sequence impedances) of a distribution transformer will be discussed in this paper.

Due to the fact that most parameters associated with the windings currently can only be measured at or around power frequency through diagnostic testing methods, the practical parameter-based FRA interpretation is not possible. To deal with this problem, the paper proposes a new approach based on the combination of different measured drivingpoint impedances and relevant analysis of the duality-based equivalent circuit in determining frequency dependent parameters associated with transformer windings. Results show that the physical FRA interpretation can be reasonable obtained for the test transformer in low and medium frequency range.
\end{abstract}

Index Terms - Driving-point impedance, duality principle, electrical parameters, frequency response analysis, transformer winding.

\section{INTRODUCTION}

$\mathrm{E}$ lectrical parameters associated with transformer windings consist of resistances,

Manuscript Received on March 15 ${ }^{\text {th }}$, 2017, Manuscript Revised on November $01^{\text {st }}, 2017$.

Dinh Anh Khoi Pham, Division of High-Voltage Engineering, Department of Power Systems, Faculty of Electrical and Electronic Engineering, Ho Chi Minh City University of Technology, VNU-HCM, Vietnam (e-mail: khoipham@hcmut.edu.vn). capacitances and dual magnetic-electrical parameters such as leakage and zero-sequence inductance. From measurement viewpoint, they can only be represented by components in the duality-based equivalent circuit at low and medium frequencies [1-4]. Since the electrical parameters are not fully determined and can only be measured in a very low frequency range, it is thus stated that the determination of all electrical parameters in broad frequency range for a reasonable FRA interpretation in low and medium frequency range is valuable and meaningful.

It is necessary to review state-of-the-art diagnostic testing methods for measurement of the winding-associated electrical parameters. Apart from conventional methods that measure transformers at power frequency, several advanced methods are developed and performed by means of specialized testing devices such as the CPC100 device in a very low frequency range from $15 \mathrm{~Hz}$ to $400 \mathrm{~Hz}$ to determine leakage and zero-sequence inductance, stray losses, ground and inter-winding capacitances [5]. Thus, these parameters are not fully beneficial for a physical FRA interpretation since the frequency range for FRA measurements is normally from $20 \mathrm{~Hz}$ to $2 \mathrm{MHz}$.

To be able to solve the problem, this paper introduces a case study in determining frequency dependent electrical parameters associated with transformer windings for FRA purpose on a $200 \mathrm{kVA} \quad 10.4 / 0.46 \quad \mathrm{kV}$ YNyn6 opened transformer. In the case study, measurements of frequency responses of driving-point impedances performed at transformer terminals by means of a scattering-parameter vector-network analyzer (VNA) of Omicron are found suitably with selected settings: low applied field $\left(1 \mathrm{~V}_{\text {rms }}\right.$ opencircuited) and broad frequency range $(20 \mathrm{~Hz}$ to 
$2 \mathrm{MHz}$ ). Other diagnostic measurements such as standard FRA, conventional and advanced diagnostic testing methods are performed by means of the VNA and the $\mathrm{CPC} 100$ for the purpose of verification.

\section{WINDING PARAMETER DETERMINATION}

This section presents how frequency dependent functions of winding parameters of the test transformer referred into the high-voltage side are developed from measurements so that the simulation of the duality-based circuit in broad frequency range is feasible.

\subsection{Duality-based equivalent transformer circuit}

The duality-based equivalent circuit of the test transformer under single-phase excitation on phase A is depicted in Fig. 1 (source is not shown) with explanation: $\mathrm{R}_{1} / / \mathrm{L}_{1}, \mathrm{R}_{\mathrm{y}} / / \mathrm{L}_{\mathrm{y}}$ are non-linear core leg and yoke components, respectively; $\mathrm{R}_{\mathrm{H}}$ and $\mathrm{R}_{\mathrm{L}}$ are resistances of high-voltage (HV) and low-voltage (LV) windings, respectively; $\mathrm{L}_{3}$ is (per-phase) leakage inductance in the tested phase; $\mathrm{R}_{4} / / \mathrm{L}_{4}$ are (per-phase) zero-sequence components [6]. Since the circuit is used for simulation at medium frequencies, widing capacitances are added as follows: $\mathrm{C}_{\mathrm{sH}}, \mathrm{C}_{\mathrm{sL}}$ and $\mathrm{C}_{\mathrm{gH}}, \mathrm{C}_{\mathrm{gL}}$ are series and ground capacitances of $\mathrm{HV}$ and $\mathrm{LV}$ phase windings, respectively; $\mathrm{C}_{\mathrm{iw}}$ are inter-winding HV$\mathrm{LV}$ capacitances $\left(\mathrm{C}_{\mathrm{gH}}, \mathrm{C}_{\mathrm{gL}}\right.$ and $\mathrm{C}_{\mathrm{iw}}$ are divided into two connected to ends of windings).

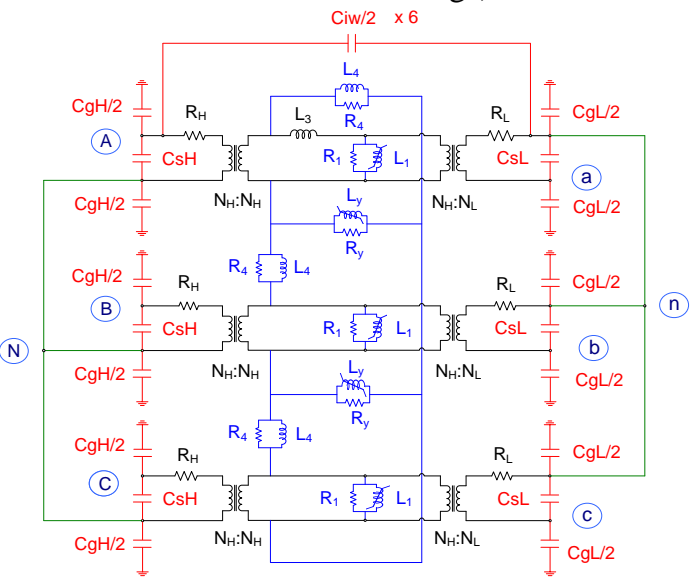

Fig. 1. Duality-based equivalent circuit of the test transformer at low and medium frequencies.

To be able to determine different parameters in the circuit, several measurements of short-, opencircuit, zero-sequence, and capacitive input impedances need to be performed so that relevant electrical parameters can be calculated.

\subsection{Determination of winding resistances and leakage inductances from per-phase short- circuit impedance tests}

A per-phase short-circuit impedance test is performed in the same manner like the relevant conventional diagnostic test, i.e. a $\mathrm{HV}$ phase winding, e.g. terminals A-N, is excited whereas the corresponding LV, terminals a-n, is short circuited. As a result, the measured impedance at low frequencies consists of two components in series: an equivalent resistance representing total stray losses ( $\left.\mathrm{R}_{\text {stray_losses }}\right)$ in real part and a per-phase leakage inductance $\left(\mathrm{L}_{3}\right)$ representing corresponding leakage flux between the $\mathrm{HV}$ and $\mathrm{LV}$ winding in imaginary part.

1) Calculation of winding resistances from $\mathrm{R}_{\text {stray_losses: }}$ In the short-circuit impedance test, the $\mathrm{R}_{\text {stray_losses }}$ consists of two main components: AC resistances of $\mathrm{HV}$ and $\mathrm{LV}$ windings accounting for eddy current and circulating current loss, resistive losses from other transformer parts (flitch plate, core edge, frame and tank) [7]. It is realized though simulation later on that any selection of factors for winding resistances $\left(\mathrm{R}_{\mathrm{H}}, \mathrm{R}_{\mathrm{L}}\right)$ from $\mathrm{R}_{\text {stray_losses }}$ is acceptable because it does not influence much the simulated frequency responses where the interactions between inductances and capacitances are of importance and interest.

2) Development of frequency dependent functions for winding resistances and leakage inductances: at frequencies lower than $10 \mathrm{kHz}$, the measured impedance is inductive. As a result, winding resistance and leakage inductance can be easily calculated from measurements and afterwards frequency dependent functions can be developed thanks to simple fitting functions [8]. At higher frequencies, frequency dependent functions of the parameters could only be obtained based on experimental formulas. For winding resistances, the formula accounting for skin effect in the form of the two-term power function in [2]: $R_{A C}(f)=$ $\mathrm{R}_{\mathrm{DC}}+\Delta \mathrm{R}_{\mathrm{AC}} \times(\mathrm{f} / 50)^{\mathrm{m}}$, where $\mathrm{f}$ is frequency and $\mathrm{m}$ is constant, can be used whereas any function which has constant tendency versus frequency such as the rational function can be considered for leakage inductance since non-magnetic materials are in leakage channels.

Fig. 2 and 3 plot the resultant frequency dependent functions of the $R_{\text {stray_losses }}$ and $L_{3}$ of phase $\mathrm{A}$ in whole frequency range, respectively. 


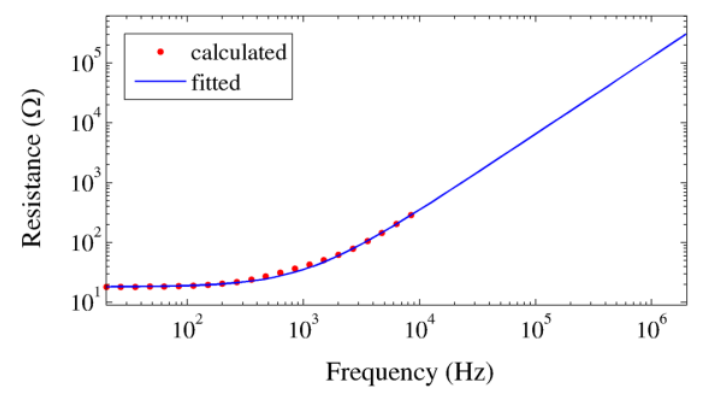

Fig. 2. Calculated and fitted equivalent resistance of total stray losses of phase A.

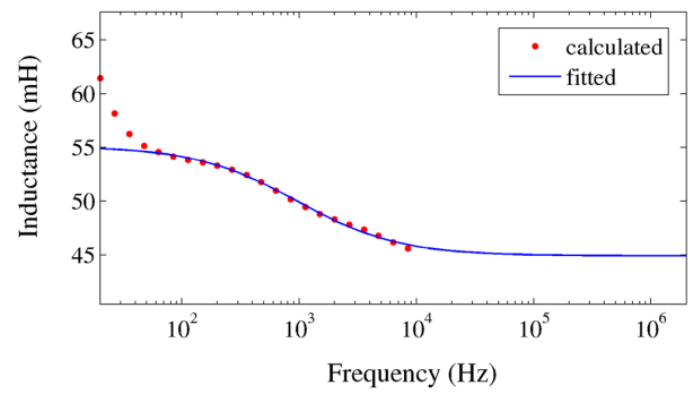

Fig. 3. Calculated and fitted leakage inductance of phase A.

In Fig. 2, good agreement between measurement-calculated values at frequencies lower than $10 \mathrm{kHz}$ shows that the chosen fitting function is efficient to represent the $R_{\text {stray_losses, }}$ from which resistances of $\mathrm{HV}$ and $\mathrm{LV}$ windings can be calculated using rough factors. In Fig. 3, the fitting function of leakage inductance not only matches with calculated values at frequency range from $100 \mathrm{~Hz}$ to $10 \mathrm{kHz}$ but also provides constant tendencies at other frequencies (lower than $100 \mathrm{~Hz}$ and higher than $10 \mathrm{kHz}$ ). The constant tendency at frequencies lower than $100 \mathrm{~Hz}$ is useful to adapt corresponding measured values in a correct way. Error of $0.13 \%$ from the comparison of leakage inductances between the conventional diagnostic testing method $(54.64 \mathrm{mH}$ measured by means of the CPC100, $1 \mathrm{~A}$ supplied) and the impedance approach $(54.57 \mathrm{mH})$ at $50 \mathrm{~Hz}$ shows that the function is appropriately selected.

\subsection{Open-circuit zero-sequence impedance from zero-sequence impedance test}

The zero-sequence impedance test is performed in such a way that the source is supplied between the three connected $\mathrm{HV}$ terminals and the HV neutral. For the test transformer, it is possible to perform two types of zero-sequence test at $\mathrm{HV}$ side since the star-connected LV winding can be left opened or shorted. Nevertheless, only the open-circuit zero-sequence test is necessary since the resultant impedances are required for analysis of the open-circuit driving-point impedances (and voltage ratios). The measured impedance has an inductive behaviour at frequency range from $20 \mathrm{~Hz}$ to $3 \mathrm{kHz}$ and a capacitive feature at higher frequencies. In the inductive region, since the total zero-sequence current is from three per-phase currents each of which flows through a HV winding resistance and a per-phase zero-sequence impedance, the per-phase zero-sequence impedance can be determined as one third of the measured impedance subtracting the HV winding resistance.

After per-phase zero-sequence impedances are calculated from measurements at frequencies from $20 \mathrm{~Hz}$ to $3 \mathrm{kHz}$, frequency dependent functions of per-phase zero-sequence components are then developed. For per-phase zero-sequence resistances $R_{4}$, the fitting function as a two-term power function of logarithm scale of frequency is best used whereas for per-phase zero-sequence inductances $\mathrm{L}_{4}$, since it represents also the linear reluctance of non-magnetic material paths outside the windings, the fitting function for leakage inductance can be applied. Fig. 4 and 5 plot fitted frequency dependent functions of per-phase zerosequence components in wide frequency range, which yield good performances at measured frequencies (for instance, error of $0.32 \%$ of zerosequence inductance compared with the conventional measured one at $50 \mathrm{~Hz}$ ) and also acceptable tendency at higher frequencies. Comparison between Fig. 3 and 5 shows that the zero-sequence inductance is appreciably higher than the leakage one since the transformer has no tank which acts as shield to confine the zerosequence flux paths. It gives a logical reason for the fact that the zero-sequence inductance influences core calculation in [6].

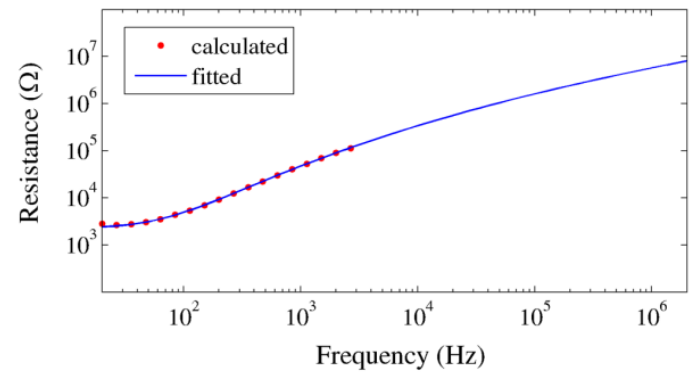

Fig. 4. Calculated and fitted per-phase zero-sequence resistance. 


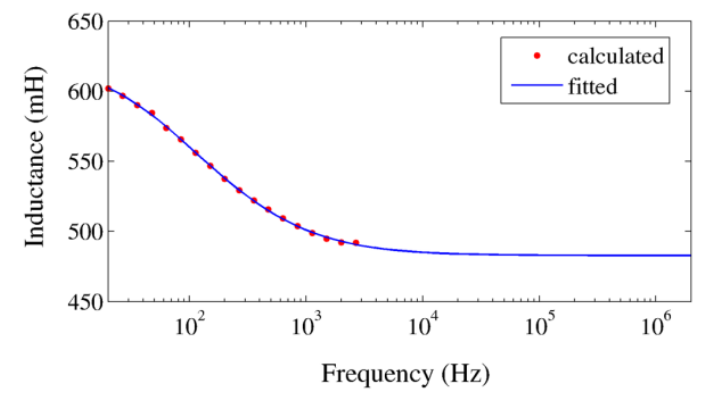

Fig. 5. Calculated and fitted per-phase zero-sequence inductance.

\subsection{Ground and inter-winding $H V-L V$ capacitances from capacitive impedance tests}

Ground and inter-winding HV-LV capacitances can be measured in the conventional capacitance test by means of the CPC100 at power frequency and high applied field. Alternatively, they can be determined from capacitive impedance tests at very low applied field but higher frequencies [9]. The capacitance model shown in Fig. 6 is derived from the circuit in Fig. 1 with HV terminals (A, B, $\mathrm{C}, \mathrm{N})$ shorted and LV terminals (a, b, c, n) shorted.

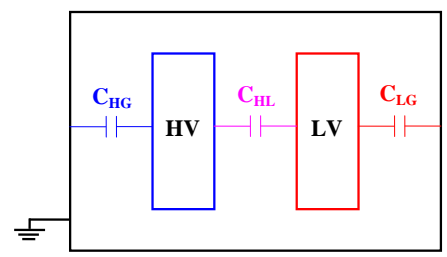

Fig. 6. Capacitance model of the test transformer.

In Fig. $6, \mathrm{C}_{\mathrm{HG}}$ and $\mathrm{C}_{\mathrm{LG}}$ are the total ground capacitances of the $\mathrm{HV}$ and $\mathrm{LV}$ windings respectively and $\mathrm{C}_{\mathrm{HL}}$ is the total $\mathrm{HV}-\mathrm{LV}$ interwinding capacitance; these total capacitances are constituted from three relevant phase winding capacitances $\left(\mathrm{C}_{\mathrm{gH}}, \mathrm{C}_{\mathrm{gL}}, \mathrm{C}_{\mathrm{iw}}\right)$ in Fig. 1 .

The procedure to calculate the capacitances from capacitive impedance tests performed by means of the VNA is based on different combinations of measurement configurations as explained in Table 1.

TABLE 1

MEASUREMENT CONFIGURATIONS IN CAPACITIVE IMPEDANCE TESTS

\begin{tabular}{|c|c|c|}
\hline No & Configuration & Equivalent capacitance \\
\hline 1 & HV excited, LV shorted & $\mathrm{C}_{\mathrm{HG}} / /\left(\mathrm{C}_{\mathrm{HL}}\right.$ series $\left.\mathrm{C}_{\mathrm{LG}}\right)$ \\
\hline 2 & HV excited, LV grounded & $\mathrm{C}_{\mathrm{HG}} / / \mathrm{C}_{\mathrm{HL}}$ \\
\hline 3 & HV shorted, LV excited & $\mathrm{C}_{\mathrm{LG}} / /\left(\mathrm{C}_{\mathrm{HL}}\right.$ series $\left.\mathrm{C}_{\mathrm{HG}}\right)$ \\
\hline 4 & HV grounded, LV excited & $\mathrm{C}_{\mathrm{LG}} / / \mathrm{C}_{\mathrm{HL}}$ \\
\hline
\end{tabular}

Table 2 presents a comparison of the capacitances from the conventional and impedance test. The conventional test is performed by means of the CPC100 at power frequency at a voltage lower than the normal applied voltage $(2 \mathrm{kV}$ instead of $10 \mathrm{kV}$ ) since the transformer has no oil and the insulations are very aged (measured dissipation factors are higher than $20 \%$ ). The high losses in insulations influence much the accuracy of capacitances in the conventional test, especially the $\mathrm{C}_{\mathrm{LG}}$. On the other hand, in the impedance tests, equivalent capacitances are extracted from measured impedances at frequencies where very pure capacitive characteristic is found, which cannot be achieved with the diagnostic test at power frequency. Therefore, the results derived from the impedance tests are considered more accurate and will be used for further analysis.

TABLE 2

COMPARISON OF MEASURED CAPACITANCES

\begin{tabular}{ccc}
\hline \hline $\begin{array}{c}\text { Cap. in } \\
\mathrm{pF}\end{array}$ & $\begin{array}{c}\text { Conventional test } \\
(\text { at } 2 \mathrm{kV}, 50 \mathrm{~Hz})\end{array}$ & $\begin{array}{c}\text { Impedance test } \\
\text { (at } 1 \mathrm{~V}, \sim 1 \mathrm{kHz})\end{array}$ \\
\hline $\mathrm{C}_{\mathrm{HG}}$ & 290 & 316 \\
$\mathrm{C}_{\mathrm{LG}}$ & 4118 & 3097 \\
$\mathrm{C}_{\mathrm{HL}}$ & 1156 & 993 \\
\hline \hline
\end{tabular}

\section{APPLICATION For PARAMETER-BASED FRA INTERPRETATION}

Since most electrical parameters of the transformer (core impedances, leakage/zerosequence impedances, winding resistances and capacitances) are determined, the parameter-based FRA interpretation is now possible.

\subsection{Interpretation of open-circuit impedance}

The circuit in Fig. 1 without winding series capacitances is first simulated by means of commercial circuit simulation software that is able to take into account the frequency dependent functions of inductive components. To illustrate a typical case of interpretation of open-circuit impedances at HV side, Fig. 7 shows comparisons between measured and simulated frequency responses of the open-circuit impedance of phase A. Since the equivalent circuit in Fig. 1 (names as "original") is valid from $20 \mathrm{~Hz}$ to $30 \mathrm{kHz}$ (see Fig. 7 ), the circuit is adjusted slightly so that the valid frequency range is extended until $100 \mathrm{kHz}$. 


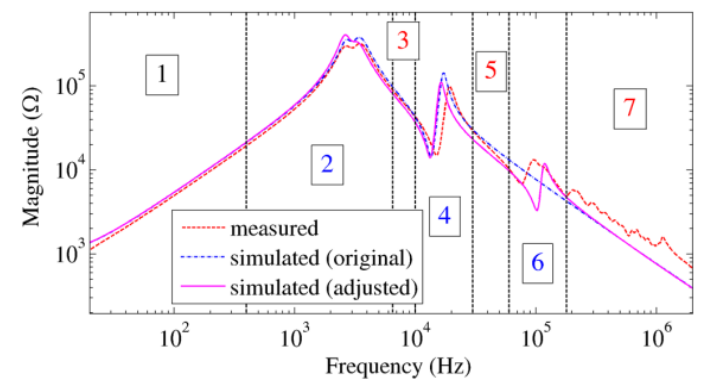

Fig. 7. Measured and simulated open-circuit input impedances observed at the $\mathrm{HV}$ winding of phase A.

From Fig. 7, several conclusions are drawn as follows.

1) Validation of core impedances: Reasonable agreements at low frequencies from $20 \mathrm{~Hz}$ to $400 \mathrm{~Hz}$ (region (1)) show that core impedances calculated in Part I [6] are acceptable.

2) Influence of series capacitances: Since there is good agreement between measured and simulated open-circuit impedances at medium frequencies where capacitive characteristic is dominant (region (3), the series capacitances of windings are small compared with other capacitances and thus can be neglected.

3) Regions of parameter influence in Fig. 7 can be interpreted as follows: Region (1): inductive core influence $(20 \mathrm{~Hz}$ to $400 \mathrm{~Hz}$ ); Region (2): interaction between core inductances and winding capacitances (from inductive into capacitive from $400 \mathrm{~Hz}$ to around $6.5 \mathrm{kHz}$ ); Region (3): winding capacitances (capacitive from $6.5 \mathrm{kHz}$ to around $10 \mathrm{kHz}$ ); Region (4): interaction between winding capacitances and total zero-sequence inductance (10 kHz to $30 \mathrm{kHz}$ ); Regions (5), (6) and (7): winding capacitances and total zero-sequence inductance (capacitive tendency at frequencies higher than $30 \mathrm{kHz}$ with the original duality-based circuit)

Since the leakage inductance is much lower than the zero-sequence inductance and is in the magnetic-electrical circuit with core and zerosequence impedances, its influence on the simulated impedance cannot be recognized. As a result, it can be stated that the duality-based transformer circuit for the test transformer is limited from low frequencies to around $30 \mathrm{kHz}$. The valid frequency range of the circuit can be extended to around $100 \mathrm{kHz}$ (region (6) in Fig. 7) if the leakage inductance is moved from the magnetic-electrical area into the winding area, i.e. in series with winding resistance $R_{H}$ and terminated with two ground capacitance $\mathrm{C}_{\mathrm{gH}} / 2$ at two ends (the adjusted circuit). In this situation, the valid frequency range broadened from $30 \mathrm{kHz}$ to $100 \mathrm{kHz}$ proves that at high frequencies, direct couplings between (distributed) leakage inductance and winding capacitances happen.

\subsection{Interpretation of the open-circuit voltage ratio}

The original and adjusted circuits are then used to simulate the "end-to-end open-circuit voltage ratio" (EEOC) test of phase A as shown in Fig. 8. At frequencies lower than $30 \mathrm{kHz}$, it is true that core impedances are validated and windings' series capacitance can be ignored since good agreements between measurements and simulations in sub-frequency ranges like those in Fig. 7 are observed. At higher frequencies, large deviations however appear, meaning that the circuit is not very suitable for standard frequency response simulations. In comparison with the original circuit, the adjusted circuit is found better since the simulated result reflects interactions of winding capacitances and leakage inductance at the end of region (4) in Fig. 8 (at around $42 \mathrm{kHz}$ ), when the inductance is moved into the winding area. Nevertheless, a lot of peaks/valleys and maximum/minimum in region (5) in Fig. 8 reveal that the duality-based circuit is no longer valid and a distributed circuit should be developed for a better analysis, as suggested from international standards [10-11].

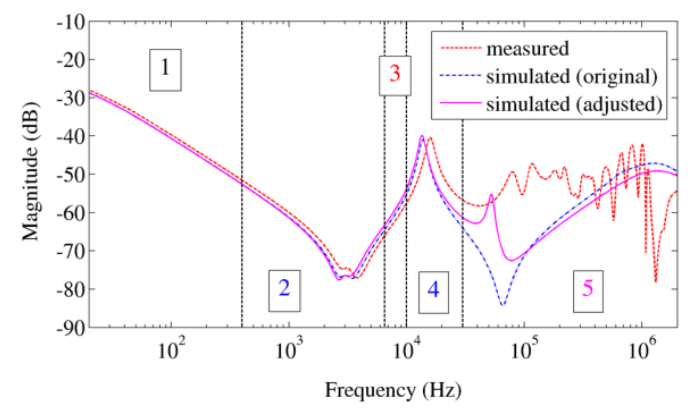

Fig. 8. Measured and simulated standard EEOC tests of the HV winding of phase A.

\section{CONCLUSION}

This paper presents a new approach in determining winding-associated parameters in the duality-based circuit based on measurements of frequency responses of driving-point impedances for purposes of FRA interpretation. In detail, frequency dependent functions of winding and zero-sequence resistances, leakage and zerosequence inductances are developed in broad range 
of frequencies, and winding capacitances are determined reasonably based on different types of impedance measurements.

For application, frequency dependent functions of inductive components and constant capacitances are helpful to interpret influences of electrical parameters in different frequency responses in broad frequency range. In addition, the simulationbased FRA interpretation is useful to determine the influence of windings' series capacitance on the total capacitance effect, which has been unsolved satisfactorily so far.

\section{REFERENCES}

[1] J.A. Martinez and B.A. Mork, "Transformer modeling for low- and mid-frequency transients-A Review", IEEE Transactions on Power Delivery, vol. 20, no. 2, pp. 16251632, April 2005.

[2] J. A. Martinez, R. Walling, B. A. Mork, J. Martin-Arnedo, and D. Durbak, "Parameter determination for modeling system transients - Part III: Transformers," IEEE Transactions on Power Delivery, vol. 20, no. 3, pp. 20512062, Jul. 2005.

[3] B. A. Mork, Francisco Gonzalez, Dmitry Ishchenko, Don L. Stuehm, and Joydeep Mitra, "Hybrid transformer model for transient simulation-Part I: Development and parameters," IEEE Transactions on Power Delivery, vol. 22, no. 1, pp. 248-255, 2007.

[4] B. A. Mork, Francisco Gonzalez, Dmitry Ishchenko, Don L. Stuehm, and Joydeep Mitra, "Hybrid transformer model for transient simulation - Part II: Laboratory measurements and benchmarking," IEEE Transactions on Power Delivery, vol. 22, no. 1, pp. 256-262, 2007.

[5] Diagnostic Testing Solutions for Power Transformers, Omicron brochure, 2011.

[6] D.A.K. Pham, "Measurement-based electrical parameters of power transformers for FRA interpretation-Part I: Core analysis," to be sent to the Journal of Science and Technology Development, VNU-HCM, 2017.

[7] S. V. Kulkarni, and S. A. Khaparde, "Stray loss evaluation in power transformers-A review," Power Engineering Society Winter Meeting, vol. 3, pp. 2269-2274, 2000.

[8] Mathwork Inc., Curve fitting toolbox.

[9] D.A.K. Pham, T.M.T. Pham, H. Borsi and E. Gockenbach, "A new method for purposes of failure diagnostics and FRA interpretation applicable to power transformers," Transactions on Dielectric and Electrical Insulation, vol. 20, no. 6, pp. 2026-2034, 2013.

[10] IEEE PC57.149TM/D9.1, Draft guide for the application and interpretation of frequency response analysis for oil immersed transformers, Mar. 2012.

[11] IEC 60076-18, Power transformers - Part 18: Measurement of frequency response, 2012.

Dinh Anh Khoi Pham was born in Ninh-Thuan, Vietnam, in 1979. He received the B.Sc. and M.Sc. in electrical engineering from the Ho Chi Minh City University of Technology, VNU-HCM in 2002 and 2004, respectively, and the Ph.D. degree in electrical engineering from the Leibniz Universität Hanover, Germany in 2013. Since 2014 he has worked as Lecturer at the Ho Chi Minh City University of Technology, VNU-HCM, Vietnam. His research interest includes simulation, testing and diagnostics of power transformers. 


\title{
Thông số điện máy biến áp lực cho phân tích đáp ứng tần số - Phần II: Cuộn dây
}

\author{
Phạm Đình Anh Khôi
}

Tóm tắt— Để ứng dụng kỹ thuật phân tích đáp ứng tần số cho máy biến áp lực (MBA), các thông số điện của lõi thép và cuộn dây cần phải được xác định trong vùng tần số rộng. Bởi vì tổng trở lõi thép đã được tính toán trong phần I, các thông số của cuộn dây (điện trở, điện dung) và các tổng trở ngắn mạch/thứ tự không của một máy biến áp phân phối sẽ được khảo sát trong bài báo này. Do phần lớn các thông số liên quan đến cuộn dây hiện nay chỉ có thể đo lường tại hay xung quanh tần số công nghiệp bằng các phép đo chẩn đoán truyền thống, việc phân tích đáp ứng tần số sẽ không khả thi. Để giải quyết vấn đề này, bài báo đề xuất một giải pháp mới xác định thông số cuộn dây dựa trên sự kết hợp giữa phép đo các tổng trở đầu cực và phép phân tích trên mạch tương đương MBA xây dựng trên nguyên lý tương hỗ. Kết quả cho thấy việc phân tích đáp ứng tần số cho MBA khảo sát có thể thực hiện được trong vùng tần số thấp và trung bình.

Tù khóa—Tổng trở đầu cưc, nguyên lý tuơng hỗ, phân tích đáp ưng tần số, thông số điện, cuộn dây máy biến áp. 